\title{
What do strokes teach us about collaborative design?
}

\author{
Catherine Elsen ${ }^{1}$, Françoise Darses ${ }^{2}$ and Pierre Leclercq ${ }^{1}$ \\ ${ }^{1}$ LUCID-ULg, University of Liège, chemin des chevreuils 1, 4000 Liège, Belgium \\ ${ }^{2}$ ACSO Department, IRBA, BP 73 - 91223 Brétigny sur Orge \\ \{catherine.elsen, pierre.leclercq\}@ulg.ac.be; fdarses@imassa.fr
}

\begin{abstract}
This paper shows that understanding collaborative design goes beyond analyzing group dynamics, tasks' repartitions or negotiation during decision-making processes. During the preliminary phases of design, the intentions of a designer are mainly supported by its sketches and more particularly by specific graphic units inside those sketches. Inside a controlled setting, twelve professional designers are asked to express, share, capture or interpret sketches. A qualitative and quantitative fine-grained analysis of strokes teach us

- how designers tend to deal with representations that are not theirs, as in an ecological collaborative situation;

- $\quad$ what main graphical key-features constitute the crucial essence of the shared information;

- $\quad$ how and when is this graphic essence ready to be shared with collaborators.
\end{abstract}

Keywords. Shared Representations, Preliminary Design, CSCW, SBIM.

\section{Introduction}

From simple and stable, working environments become today increasingly complex and dynamic [1]. Designing tasks (architectural design, industrial or product design, engineering, town planning, ...) are nowadays highly challenged by the geographic dispersion of resources, tasks and skills. Preliminary design phases, with their divergent and abundant creative processes and their constant re-definition of the problem and solution spaces, are shifting more and more from individual to collaborative contexts and are particularly prone to be impacted by this evolving paradigm. Preliminary design phases are crucial, though: Ehrlenspiel demonstrated that in engineering, more than $70 \%$ of the project's final costs are somehow determined during the 30 first $\%$ of the design process [2].

Several usages, strategies (and sometimes procedures) somehow foster this soon-to-be-generalized collaborative ideation practice; among them, this paper will focus on one very crucial aspect: the cooperative emergence of shared representations (more specifically free-hand sketches) and of shared content.

Face-to-face collaborative work naturally engages actors (with or without drawing capabilities) to use free-hand sketching, still one of the best design tools available to support the fast, intuitive, ambiguous and blurred expression of emergent (design) concepts as well as the cognitive synchronization between various stakeholders [3-5]. Until recently, such sketching activity was hardly perpetuated during remote collaborative design, which was limited to textual or vocal interaction (telephone, mail, ...) or, at best, asynchronous annotation and editing of documents. Now, new generation of sketching and annotating interfaces supported by a variety of graphic tablets and/or immersive environments (such as SketSha, see [6] or the Hybrid Ideation Space, see [7]) enable users to get involved in more faithful, intuitive and efficient ideation, even distantly.

Thus, side-by-side with studies unfolding the various aspects and modalities of front-to-front and traditionallyequipped collaborative work, a large community of researchers now focuses on how current digital environments do support (or impair) distant collaborative work and how to specify new tools to efficiently equip such remote design activities. The next sections will show how this specific community accumulates insights on stakeholders' behaviors during collaboration and on the management and evolution of shared external representations but, on the other hand, how the graphic essence of these representations tend to be less investigated. Through a fine-grained analysis of this graphic content, this paper will show which, how and when graphic units are transferred and interpreted by distributed designers, and how these results can inform the development of support tools more adapted to practitioners' needs and expectations.

\section{$2 \quad$ Related Work}

\subsection{Design as a Collaborative Task}

Design, indistinctly from its field, largely becomes a collaborative activity. Even as soon as preliminary design, very few projects still grow from the intentions of a single designer. And when it is still the case, one could argue that this 
designer, including in its program the various needs and requirements of an increasing number of end-users and stakeholders, is not «alone» anymore (even conceptually) to control and dictate the paths the project might take.

«Designing together» or «in participation» takes several names and modalities, depending on how actors articulate their goals, tasks and strategies. No consensus can really be found in the existing literature between the definitions of collaboration, cooperation, co-action (here, co-design) or distributed design. Beyond these definitions, highly dependent of their context of elaboration, Détienne, Boujut and Hohmann [8] rather define three classes of activities: task-oriented (or content-oriented), process-oriented (including coordination, synchronization, building of common knowledge) and interaction management activities (communicating and making sure the message has been understood). In this paper, we will mainly relate to the context of «radical» co-design or «extreme collaboration» occurring during task-oriented activities, defined by Shaw as a process «where actors engage in highly productive, [...] intense collaboration, doing work together, in real time, rather than talking about what they intend to do later independently» [9, p.22]. Next section will show how external representations inside such extreme collaboration (local or distant) contribute in conveying, capturing and crystallizing the decision-making process.

\subsection{Representations and Collaborative Design}

Beyond encapsulating design specifications, external representations (understood here as somehow persistent, i.e. not the gestures or verbal interventions) play a crucial role in mediating the collaboration.

Their functions are highly documented and several theories do exist, such as the concept of representations being intermediate or boundary objects. Vinck and Laureillard, for instance, list all the role boundary objects can play: a «spokesman» or retrospective role (tracking the design rationale); a prospective role (supporting the emergence of the object being designed); a mediating role; a prescriptive role or a «facilitator» one [10]. Bødker [11], in addition, makes a distinction between «within practice» roles (insuring fluidity, facilitation, openness) and «crossing-boundaries» ones (insuring stability and closure).

Holford and his colleagues underline how dynamic and co-constructed the representations and their content are, alwats in constant evolution. However, even if representations are intrinsically linked to their graphical contents, these essential units do foster much less research. Fong assigned 10 characteristics to boundary objects that may contribute to their effectiveness [both quoted in 12]: among those, «granularity», «malleability», «understandability» or «acessibility» could be extended to the graphical contents a representation conveys. Studying the digital annotations (verbal, gestural, graphical) produced during a term-long remote architectural studio, Safin, Juchmes and Leclercq go more deeply into the analysis of this specific graphical content (its use, its evolution, the intended goal and message) in parallel with a fine-grained understanding of the collaborative mechanisms [13]. As three main collaborative strategies emerge (distributed design, co-design and what could be called «conflicting» distributed design), the authors underline how these collaborative modalities do impact the way architectural students annotate. In all scenarii, authors distinguish several roles served by annotating documents, such as drawing attention, putting elements in correspondence, contextualizing, and synthesizing on top of completing and adding information to the representation.

One could summarize all these roles as the intentions the designer wants to transfer: an intention to share, to explain, to be understood, to be listened to. Even in contexts of extreme collaboration (where all actors intensely participate to the building of the same idea and the conditions are supposed to be the bests to share common understanding), each participant's wish is to see its message clearly transmitted. One can make sure her idea has been immediately correctly understood; but the intent of some annotations (and, by extent, any graphical content) is sometimes ephemeral and beyond a certain period, one can never be sure misunderstanding and misinterpretation won't occur. If later reinterpretation can foster unexpected discoveries (generally considered as positive), design actors may nevertheless want to graphically consolidate long-lasting decisions. The only way for them to crystallize as durably as possible their intentions is to use certain key-features: graphical and textual annotations are some of them, and further research is needed to study how other type of graphical units may also play this role.

\subsection{Graphical Content and Collaborative Design}

Considering the evolution of the preliminary design activity from designer-centered to team-centered, one can also observe impacts in terms of tasks' repartitions, roles and hierarchical structure. Our previous work already showed how the evolution of the design tools' uses (and, more specifically, Computer Aided Design tools) exhorted the designers to work sooner in close collaboration with draughtsmen [14]. Collaboration and coordination in this case occurs mainly in front of the draughtsman's screen(s), but we also observed draughtsmen unexpectedly starting to sketch to make some modifications more easily understandable to their colleagues. Sketches, undoubtedly the favorite medium of designers 
to quickly share understanding, also reveal themselves powerful collaboration tools for and between actors from different backgrounds.

Unlike most designers, though, these other actors (engineers, marketing people, even sometimes customers) do not master the art of free-hand drawing: they didn't learn the rule of perspective drawing, the importance of shades nor the use of thick lines to describe external edges. It is amazing to see how, though, they succeed in understanding and expressing their point graphically. In the process of recopying an architectural representation, students in mechanical engineering managed to understand and convey the intended message through hesitant doodles and scribbles - not as beautifully as architects of course, but sufficiently well and, astonishingly, by exploiting the same symbols and graphical clues (see [15] for more details). This reveals a way of graphically transmitting a message that seems to transcend the level of expertise and the skills and that has been seldom studied.

Strokes, seen as graphical units, have yet been the subject of numerous research: Do and Gross for instance worked on taxonomies of strokes inside architectural representations [16], while Tovey and Richards [17] focused on industrial and automotive design fields; Tversky [18] is acknowledged for her work on semantic contents, while Do [19] or Dessy [20] analyzed the frequency of strokes' apparition inside representations. Several levels of drawing complexity and contents are defined by McGown, Green, and Rodgers [21] and among them, annotations alone remain the focus of a large sub-community [22-24]. As a matter of fact, if results can be found on strokes seen as graspable and repeatable units of analysis, very few research do attempt to understand what type of graphical units really builds and carries the main message of the designer - what, inside this accumulation of dots and lines, constitutes the main (maybe universal ?) essence of the shared representation.

\subsection{Research Gap and Research Questions}

The previous state-of-the-art underlined how collaborative modalities and strategies remain an important field of study and how, on the other hand, the graphical essence of a shared intention has been subjected to less attention.

Beside helping design actors to avoid misunderstandings and time lost in superfluous cross-checking iterations, this research gap holds tremendous promises for the development of new CSCW (Computer Supported Cooperative Work) tools. Empirical results are indeed expected to improve the development of such support tools. If the problem of late misinterpretations has been already exposed, precocious and misplaced interpretation of a yet-in-progress content is, for instance, an issue rather encountered by contemporary SBIM (Sketch Based Interfaces for Modeling) prototypes. Software engineers, lacking empirical data, have to make assumptions during the implementation of such tools (see for instance the drying ink and timing of strokes' interpretation in [25] or the discussion about EsQUIsE timing of 3D interpretation in [26]). If some of these decisions are intuitively sound, some other may be further informed by a deeper analysis of designers' needs and practices.

Far from dealing with all aspects of this research gap, this paper will focus on the following research questions:

- what graphic essence is really conveying the essence of the shared representation (here, free-hand sketches)? i.e., what is the graphic essence that designers do perceive, interpret and exploit as they engage in collaborative activities?

- on the other hand, what kind of graphic content is rather misinterpreted and deviated from its initial intention, i.e. is rather unequipped to the correct transmission of an intention?

- when is the crucial content ready to be submitted to collaborators (or, by extension, to support tools)?

\section{$3 \quad$ Methodology}

Our previous work largely builds on qualitative and on-site observation (see previous work quoted in section 2). We are convinced by the richness these methodologies offer in terms of fine-grained understanding of a complex and unpredictable task such as designing. But to get data to answer our specific research questions, a more systematic and controlled protocol had to be defined.

As engineering students perceiving, interpreting and extracting the essence of an architectural representation had been our topic for previous research (see above, [15]), we rather selected this time professional designers issued from various fields (consumer design, furniture design or naval design) to take part to our experiment. We suspected to get more systematic results by observing experts in their way of conveying an intention through dots and strokes, as they master the art of free-hand drawing.

Thus, twelve professional designers took part (separately) to a one hour controlled experiment including semidirective interviews as well as digital sketching on a graphic tablet. We divided them into two groups: the seven designers belonging to the first group (the «initiators») were asked to generate ideas starting from scratch, using a 
graphic tablet and a digital sketching application (see below). Each participant in this group was submitted one of the three different design briefs, considering her field of expertise: one prompt related to the design of a cafeteria tray for children, the second one to a piece of public furniture, the last one to a yacht. Respecting each participant's respective field of expertise had a double goal. First, as each designer claimed a different drawing background, we wanted them to stay as much as possible inside their comfort zone, so they would draw as freely and as naturally as possible. Second, mixing designers from various backgrounds (in design; in drawing) would enable us to evaluate how systematic the essential graphic units were. Designers knew their sketches would be later reused, but had no idea we were specifically interested in the graphic units nor the visual characteristics of their drawings (this, to some extent, does seem quite ecological as professional designers do generate, even for internal meetings, drawings they intend to communicate).

Once all "initiators" had achieved their design task (in about 45 minutes each), three of the most complete projects (in terms of easiness in understanding the designer's intentions and exhaustiveness) were selected to serve as the initial data for the second group of designers. Each of the five designers of this second group (the «pursuers») thus received the sketches anonymously drawn by three of the seven «initiators» as well as a similar design prompt that the one shown to the first group (again considering respective field of expertise). This time the pursuers were asked to take over the launched project (using the same drawing devices) as if the first colleague was suddenly no longer on the project, leaving no information other than the sketches.

We asked all designers to "think aloud" during their process of generating or "capturing-interpreting-appropriating" the project, in order to gain data about the intentions behind specific strokes, about their perception of the sketch, which key-features were useful to express or to understand an intention, and how they intended to keep the project going. Seven designers thus assumed the role of "idea initiator" and five others the role of "idea pursuer" (see table 1), all twelve limiting their work to preliminary design solutions, as the results will show.

Table 1. Outline of the experimental plan.

\begin{tabular}{|l|l|l|}
\hline Experiment $\mathbf{n}^{\circ}$ /Designer $\mathbf{n}^{\circ}$ & \multicolumn{1}{|c|}{ Design prompt } & \multicolumn{1}{|c|}{ Task } \\
\hline 1 & Tray & Generator - Group 1 \\
\hline 2 & Tray & Generator - Group 1 \\
\hline 3 & Tray & Generator - Group 1 \\
\hline 4 & Tray & Group 2 - builds on the work of Designer 3 \\
\hline 5 & Tray & Group 2 - builds on the work of Designer 3 \\
\hline 6 & Public Furniture & Generator - Group 1 \\
\hline 7 & Public Furniture & Generator - Group 1 \\
\hline 8 & Public Furniture & Group 2 - builds on the work of Designer 6 \\
\hline 9 & Public Furniture & Group 2 - builds on the work of Designer 6 \\
\hline 10 & Yacht & Generator - Group 1 \\
\hline 11 & Yacht & Generator - Group 1 \\
\hline 12 & Yacht & Group 2 - builds on the work of Designer 10 \\
\hline
\end{tabular}

Each generative task was preceded by a short exercise in order to help the designers familiarize themselves with the intuitive and easy to use Wacom Cintiq ${ }^{\circledR}$ Graphic tablet running a dedicated sketching application (Tragere prototype, see [27], figure 1). This application, modeling the interaction between a carbon lead eroding on a granulous paper, has been unanimously recognized by all twelve designers as very closely visually reproducing the real interaction between a pen and a sheet of paper (several hardnesses of leads being available, the tablet being sensitive to pressure and inclination). The feeling of drawing with a digital pen on a glassy surface, though, wasn't as convincing. Even if these aspects certainly did impact our results, some recent research showed that high-level processes (i.e., functions and behaviors inside the FBS theoretical framework) were not intrinsically modified by such digital devices [28]. This digital environment was used because it enables further trace-to-trace strokes' analysis, with a much better resolution than regular pen and paper. Dynamic screenshots were thus collected, each session was moreover video recorded, and semi-directive interviews were conducted as a debrief of the task. 


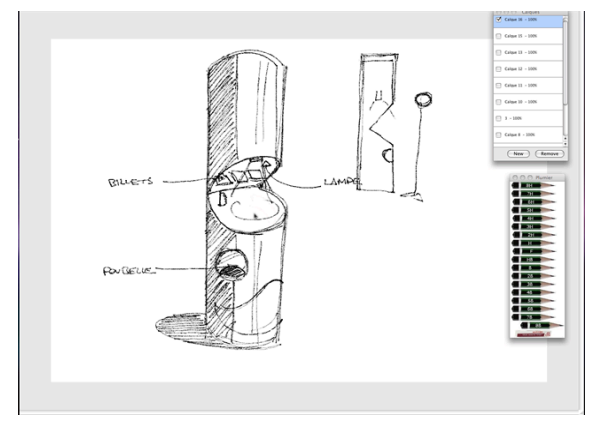

Fig.1. Tragere sketching application and its intuitive interface: a simple digital pen-box including a virtual rubber and a layer management tool.

The data collected was then segmented in short clips and coded using 7 variables and their values (see table 2). Inside these variables, the type of externalization simply refers to the type of drawing produced: is it a perspective, or an elevation? Is it only annotation, perhaps a simple designation tag?

The "general goal" values are the main objectives the representation supports: it covers very techno-centred goals (such as assembly, dimensioning) or, on the other hand, more aesthetic and functional propositions (some occurrences sometimes indistinctly answering both).

The «exhaustiveness» variable evaluates how complete (or incomplete) a sketch can be, at the scale of the whole drawing or considering a more limited part: could one understand what the unit is about, independently of the context ?

Going deeper in the fine grained analysis of the strokes, we code the type of trace and its chronological appearance. Different levels of strokes are observed, some of them occurring in specific cycles during time. Cycles of blurred crystallized strokes appear, and sometimes repeated strokes are added to generate what we call "B-R-C" cycles of strokes (for "blurred-repeated-crystallized").

The "recovery" (level of) considers the extent to which designers of the second group (the "idea pursuers") capture the graphic content of the sketches they receive: do they totally recopy the stroke, or perhaps only partially, before making it theirs ? Could we at least observe some visual evaluation (expressed through speech, designation, gesture ?), or is the stroke completely dismissed (the pursuer neglecting the work of his/her virtual colleague and starting from scratch)? By comparing sketches from both «initiators» and «pursuers», we then assess the quality of the appropriation, i.e. how faithfully or wrongly the pursuer appropriated the intent of each stroke.

The "type of curve" refers to "principal" and "secondary" curves. Principal curves persist throughout the design process: they can still be seen in the final representation. Secondary curves, on the other hand, disappear from the drawings and therefore don't strategically structure them.

One hundred thirty-one actions were thus coded (their definition depending highly on the context and on how designers shifted from one topic to another), and cross analysis of concurrent occurrences enabled both qualitative and quantitative approaches of the data, as shown in next section.

Table 2. Coding grid: 7 variables and their values.

\begin{tabular}{|c|c|c|c|}
\hline Type of externalization & General goal & Exhaustiveness & Type of trace \\
\hline annotation & technical & complete & \multirow{7}{*}{$\begin{array}{l}\text { axis } \\
\text { alpha-num } \\
\text { crystallized } \\
\text { blurred } \\
\text { blurred > cryst } \\
\text { repeated }\end{array}$} \\
\hline section & assembly & incomplete & \\
\hline elevation & dimensioning & & \\
\hline perspective & production & & \\
\hline scheme & aesthetical & & \\
\hline $\operatorname{tag}$ & aesthetico - functional & & \\
\hline & functional & & \\
\hline Recovery & Quality of appropriation & Type of curve & B-R-C \\
\hline total & erroneous & principal & shadows - textures \\
\hline partial & modified & secondary & any form \\
\hline none & faithful & & geom. Primitives \\
\hline evaluation & & & symbols \\
\hline
\end{tabular}




\section{$4 \quad$ Results and Discussion}

Organizing an experiment about shared content and defining an individual setting instead of a collaborative one showed limited effects on the results' validity. On the contrary, qualitative analysis of the verbatim showed that the «initiators», knowing that their sketches were going to be later reused, put a bigger emphasis on which graphic clues they wanted to communicate, thus underlying (but maybe in a caricatured manner) the phenomenon we were looking at. The follow-up designers, on the other hand, knew they had to deal with sketches that weren't originally theirs, and therefore did verbalize more clearly which elements they were taking into account (or neglecting) and why. The analyses moreover showed no particular impact of the design or drawing-background on the results.

All designers expressed their concepts mainly through perspectives $(51,2 \%$ of occurrences) and elevations $(32,8 \%)$ while sections were used in less than $5 \%$ of the cases. Annotations, interestingly, do only count for 8,4\% and were used by initiators and pursuers equally. This shows that annotations, even if they remain an important channel of transmitting an intention, largely share this task with other graphic units.

All designers also remained inside an abstract, conceptual ideation phase. They had limited time to proceed with the task and rarely reached technical questions or concerns generally related to later design phases. Table 3 moreover shows how the three main types of externalization support formal or rather technical questions. Annotations, surprisingly, play an important role in conveying the few technical data the designers decided to deal with. It seems that different types of graphical units may support different types of intentions.

Table 3. General goals inside the three main types of externalization (in $\%$ of occurrences).

\begin{tabular}{l|l|l|l} 
& Perspective & Elevation & Annotation \\
\hline aesthetical & $36,2 \%$ & $21,9 \%$ & $0 \%$ \\
\hline aesthetico-functional & $21,3 \%$ & $36,6 \%$ & $0 \%$ \\
\hline functional & $36 \%$ & $31,7 \%$ & $57,1 \%$ \\
\hline Total «formal» & $93,5 \%$ & $90,2 \%$ & $57,1 \%$ \\
\hline technical & $0 \%$ & $2,4 \%$ & $28,6 \%$ \\
\hline assembly & $4,9 \%$ & $2,4 \%$ & $0 \%$ \\
\hline dimensioning & $0 \%$ & $0 \%$ & $14,3 \%$ \\
\hline production & $1,6 \%$ & $2,4 \%$ & $0 \%$ \\
\hline Total «technical» & $5,5 \%$ & $7,2 \%$ & $42,9 \%$
\end{tabular}

Considering how the five «pursuers» did recover the strokes and how correctly they understood them, figure 3 shows that very few graphical units are totally recovered (i.e., recopied) while $37 \%$ of them are rather partially transmitted. $58 \%$ of the units are even or completely neglected, or at least just visually acknowledged. Among the strokes totally or partially recovered, very few erroneous interpretations were yet observed (6\%). This means that the intent has been mainly correctly understood, even if in $67 \%$ of the cases the pursuers took the liberty to divert the stroke and to appropriate the concept differently (figure 4).
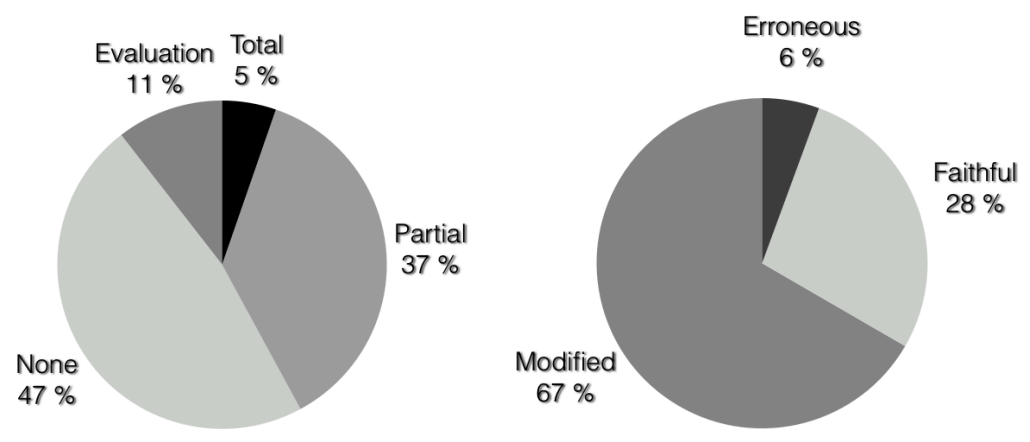

Fig. 3 (left). Level of strokes' recovery. Fig 4 (right). Quality of appropriation. In \% of actions, for the five «pursuers» only. 
Looking now more closely at the type of strokes encountered, figure 5 shows that when a recovery was total, the type of stroke was systematically defined as «principal» (i.e., the one that subsists in time and thorough the project), while it was also the case in $78,6 \%$ of the partial recoveries. Secondary curves, on the other hand, tended to be more often completely neglected or just visually acknowledged. Figure 6 yet tempers these findings, as $31,5 \%$ of the principal curves were still not fully considered (i.e., completely dismissed or visually evaluated).
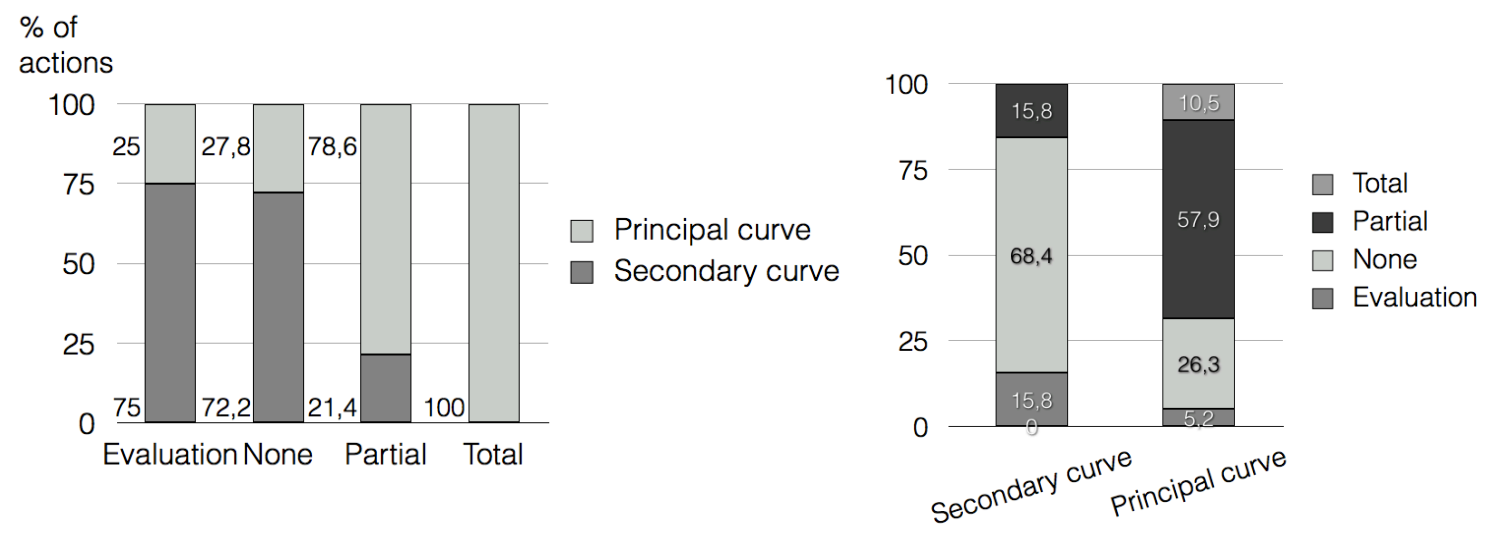

Fig. 5 (left). Level of strokes' recovery and type of curve. Fig. 6 (right). Link between the type of curve and the level of recovery. Other lecture.

Figure 7 shows how well these principal and secondary curves have been appropriated. Interestingly, not a single principal curve was erroneously identified in its meaning - if $71,4 \%$ of them are somehow modified, they still seem to constitute an important clue of the «initiator's» intention. Secondary curves, on the other hand, are subjected to more mistakes: in $25 \%$ of the cases, the pursuers completely misunderstood their intended message.

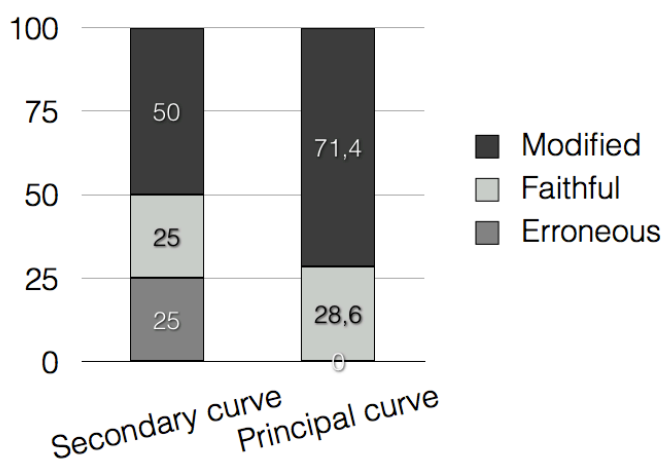

Fig. 7. Quality of appropriation of both secondary and principal curves.

The nature of these principal and secondary curves is presented in figure 8. As the graph shows, the principal curves constitute the main proportions of structural axes (dotted lines), highly recognizable geometrical primitives (i.e. a circle, a cone,...$)$ as well as of crystallized and repeated strokes or quickly performed «B-R-C» cycles of strokes (for «blurredrepeated-crystallized»). Very blurry, uncertain strokes sometimes do reappear alone (i.e., not inside the rapid construction of a cycle), but are then completely part of secondary curves. Most of light strokes (i.e., strokes that have as single meaning the geometrical construction of the drawing, for instance converging lines towards vanishing points in perspectives) as well as shadow lines are classified as secondary, as they might disappear at some stage of the process. This shows that systematic graphical principles do constitute principal curves and might therefore be the main essence of the transmitted intent. 


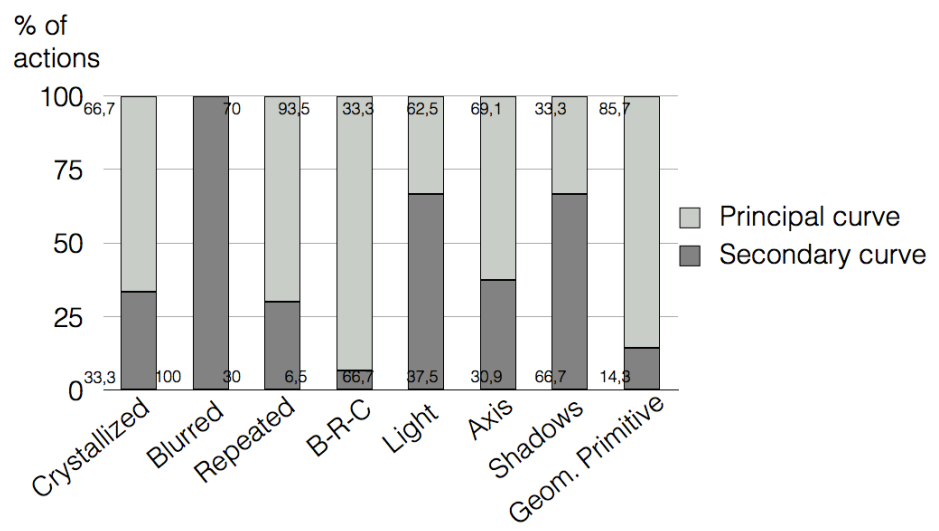

Fig. 8. Types of curves and graphical content.

Looking at figure 9, though, helps us realize that even crystallized strokes may be largely neglected when standing alone (suggesting why misunderstandings and misinterpretation continue to appear when the drawing is transmitted without a complementary verbal explanation). They nevertheless remain the single type of stroke that is totally recopied, translating the important role they play in the transmission and appropriation of the intention. Cycles of strokes tend to foster more interest, even partially. Annotations, amazingly, are completely neglected (no clue of even a visual acknowledgment): would that mean that designers loose their time in tempting to explain and transfer through annotation? We would rather suggest that designers use annotations to reference their own work, to consolidate some decisions and to insure a stability in the understanding of their own creativity, rather than with the intent to share some crucial information.

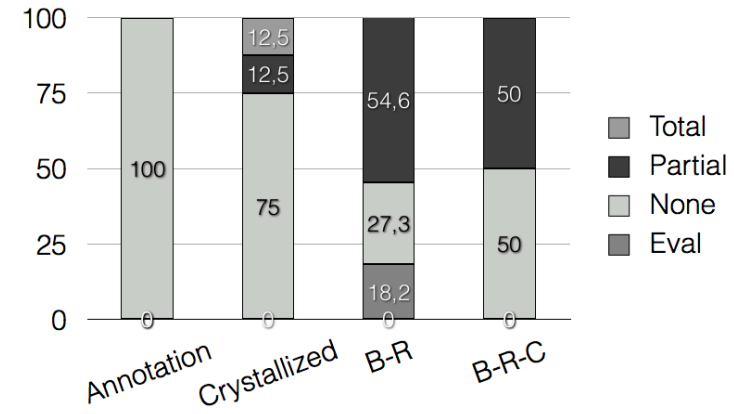

Fig. 9. Level of strokes' recovery and graphical content.

The last graph (figure 10) shows the chronological evolution of strokes. Going from principal to secondary and constituting rather complete or incomplete «objects», this graph demonstrates how constantly evolving the contents are, and how incomplete the drawing might stay during preliminary design processes. The connected "complete and principal curves" points on the graph constitute the best chances for an external observer to correctly catch the main meaning of the drawing. It also underlines to which extent the strokes and cycles of strokes need time to unfold to become principal curves and, eventually, to fully express the designer's intentions.

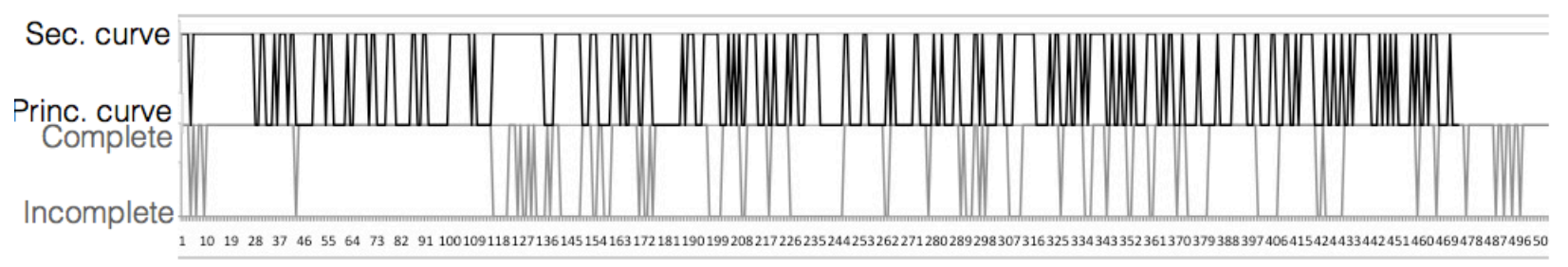

Fig. 10. Chronological evolution of curves (principal or secondary) in relation with the level of exhaustiveness.

\section{$5 \quad$ Conclusions and Future Work}

As for the field of product design, our results show that shared sketches are built upon specific strokes (or cycles of strokes) that constitute their crucial essence during collaborative design (the intention being totally, or at least partially understood and appropriated by collaborators). We believe that these cycles of strokes are the externalization of the seetransform-see process [29]. 
These principal curves consequently are the best clues software engineers have at their disposal to capture and to support sketches during preliminary design: their analysis provides interesting insights about the temporality and type of collaborative assistance new type of CSCW tools should provide to professional designers in order to effectively support their graphical cooperation, being local or remote. Considering the specific setting of these experiments, we would thus suggest that digital principal curves should not be beautified and treated as soon as they are drawn. The iterative crystallization process itself is part of the design process, and the materialization of those curves is a crucial step to insure the global coherence of the project and mutual understanding. There is a need to preserve their ambiguity and to leave designers enough time to fully develop them before any computer processing.

This paper also suggests paths for future work: annotations, even if translating personal information, may not be the unique (or even main) way for designers to graphically share intent. Principal curves, built upon a succession of blurred, repeated, crystallized strokes or geometrical primitives, are the main visual information designers generally exploit in order to express and/or capture an intention. These results constitute interesting clues for further investigation including different experimental settings and observed fields.

\section{References}

1. Spear, S. J. (2010). The high-velocity edge - How market leaders leverage operational excellence to beat the competition. McGraw Hill Professional, $432 \mathrm{p}$.

2. Ehrlenspiel, K.: Integrierte Produktentwicklung. Methoden für Prozeßorganisation, Produkterstellung und Konstruktion. Hanser, München (1995).

3. Cross, N. (2000). Strategies for Product Design, Third Edition : The open University, Milton Keynes.

4. Visser, W. (2006). The cognitive Artifacts of designing . London: Eds Lawrence Erlbaum.

5. Suwa, M., Purcell, T., \& Gero, J. (1998). Macroscopic analysis of design processes based on a scheme for coding designers' cognitive actions. Design Studies, 19 (4), 455-483.

6. Elsen, C., \& Leclercq, P. (2008). "SketSha" - The Sketch Power to Support Collaborative Design. In Y. Luo (Ed.), Cooperative Design, Visualization, and Engineering (Vol. 5220, pp. 20-27): Springer Berlin / Heidelberg.

7. Dorta, T., Kalay, Y., Pérez, E., \& Lesage, A.-M. (2011). Comparing immersion in remote and local collaborative ideation through sketches: a case study. Paper presented at the CAAD Futures 2011.

8. Détienne, F., Boujut, J.-F., \& Hohmann, B. (2004). Characterization of collaborative design and interaction management activities in a distant engineering design situation. Paper presented at the COOP 2004 - Cooperative systems design: scenario-based design of collaborative systems.

9. Shaw, B.G. (2007). «More than the Sum of the Parts: Shared Representations in Collaborative Design Interaction». Thesis Royal College of Art, $292 \mathrm{p}$.

10. Vinck, D., \& Laureillard, P. (1996). Coordination par les objets dans les processus de conception. Paper presented at the Journée CSI "Représenter, coordonner, attribuer".

11. BØdker, S. (1998). «Understanding Representation in Design». Human-Computer Interaction. 13, 2. 107-125

12. Bugeaud, F., Giboin, A., \& Soulier, E. (2010). Shared Representations for Innovation: Experience Feedback on Two Innovation-oriented Projects. Paper presented at the COOP'10 Workshop: The mediation role of shared representations in cooperative activities: new challenges.

13. Safin, S., Juchmes, R. \& Leclercq, P. (2012). «Use of graphical modality in a collaborative design distant setting». In Work: A Journal of Prevention, Assessment and Rehabilitation, Vol. 41, Suppl. 1/2012, pp. 3484-3493, IOS Press.

14. Elsen, C., Darses, F., \& Leclercq, P. (2010). An Anthropo-based Standpoint on Mediating Objects: Evolution and Extension of Industrial Design Practices. In J., Gero, Design Computing and Cognition 2010. (pp.55-74) Berlin, Germany: Springer Berlin / Heidelberg.

15. Elsen, C., Demaret, J-N., Yang, M-C., and Leclercq, P. (in press). Sketch-Based Interfaces for Modeling and Users' Needs: Redefining Connections. AIEDAM Vol. 26, n³.

16. Do, E., \& Gross, M. (1997). Inferring design intentions from sketches: an investigation of freehand drawing conventions in design. Paper presented at the CAADRIA 1997, Taiwan.

17. Tovey, M., \& Richards, C. (2004). Computer representation for concept design and maintenance instruction. Paper presented at the TMCE 2004, Lausanne.

18. Tversky, B. (2002). What do Sketches say about Thinking. Paper presented at the Proceedings of the 2002 AAAI Spring Symposium.

19. Do, E. (1995). What's in a diagram that a computer should understand. Paper presented at the CAAD Futures '05, Singapour.

20. Dessy, J. (2002). De l'emploi des symboles dans les esquisses architecturales. Université de Liège, Liège.

21. McGown, A., Green, G., \& Rodgers, P. A. (1998). Visible ideas: information patterns of conceptual sketch activity. Design Studies, 19 (4), 431-453.

22. Boujut, J., Darses, F., \& Guibert, S. (2007). Etude des annotations en situation collaborative de conception mécanique. In P. Salembier \& M. Zacklad (Eds.), Annotations dans les documents pour l'action (pp. 127-152). Paris: Lavoisier.

23. Hisarciklilar, O., \& Boujut, J. (2009). An annotation model to reduce ambiguity in design communication. Research in Engineering Design, 20 (3), 171-184.

24. Zacklad, M., Lewkowicz, J. F., Darses, F., \& Détienne, F. (2003). Formes et gestion des annotations numériques collectives en ingénierie collaborative . Paper presented at the Actes d'IC 03, Laval.

25. Bae, S.-H., Balakrishnan, R., \& Singh, K. (2008). ILoveSketch: as-natural-as-possible sketching system for creating 3d curve models . Paper presented at the Proceedings of the 21st annual ACM symposium on User interface software and technology, Monterey, CA, USA.

26. Darses, F., Mayeur, A., Elsen, C., \& Leclercq, P. (2008). Is there anything to expect from 3D views in sketching support tools ? Paper presented at the Design Computing and Cognition '08 : Proceedings of the Third International Conference on Design Computing and Cognition., J. Gero and A. Goel, Atlanta, USA Springer! : 283-302.

27. Jeunejean, A. (2004). Algorithme de tracé réaliste pour environnement de dessin virtuel . Faculté des Sciences Appliquées. Liège, Université de Liège. Master Thesis.

28.Tang, H., Lee, Y., \& Gero, J. (2010). Comparing collaborative co-located and distributed design processes in digital and traditional sketching environments: A protocol study using the function-behaviour-structure coding scheme. Design Studies , 1-29.

29. Schön, D. A., \& Wiggins, G. (1992). Kinds of seeing and their functions in designing. Design Studies, 13 (2), 135-156. 